\title{
Referrals from Paediatric Department with Respiratory Symptoms having Skin Lesions
}

\section{Sagar Mani Jha ${ }^{1}$, Lee Budhathoki ${ }^{2}$, Nabin Bhakta Shakya ${ }^{1}$, Sunil Shakya ${ }^{1}$ and Kumar Roka ${ }^{3}$}

${ }^{1}$ Department of Dermatology and STI, Nepalese Army Institute of Health Sciences, Shree Birendra Hospital, Chhauni, Kathmandu, Nepal

${ }^{2}$ Department of Community Medicine, Nepalese Army Institute of Health Sciences, Shree Birendra Hospital, Chhauni, Kathmandu, Nepal

${ }^{3}$ Department of Internal Medicine, Nepalese Army Institute of Health Sciences, Shree Birendra Hospital, Chhauni, Kathmandu, Nepal

\author{
Correspondence: \\ Sagar Mani Jha, \\ Department of Dermatology and STI, \\ Nepalese Army Institute of Health \\ Sciences, Kathmandu, Nepal. \\ Email: sagarmanijha@gmail.com
}

DOI: $10.3126 /$ jnps.v41i1.35184

Submitted on: $2020-08-18$

Accepted on: 2021-02-14

Acknowledgements: Dr Manisha Maharjan, resident in the Department of Dermatology and STI for assisting in data management.

Funding: Nepalese Army Institute of Health Sciences were used

Conflict of Interest: None declared Permission from IRB: Yes

To cite this article: Jha SM, Budhathoki L, Shakya NB, Shakya S, Roka K. Referrals from Paediatric Department with Respiratory Symptoms having Skin Lesions. J Nepal Paediatr Soc. 2021;41(1):87-92.

\begin{abstract}
Introduction: Paediatric patients with respiratory symptoms having skin lesions are often referred from Paediatric to Dermatology Department. Knowledge about skin and respiratory manifestations will lead to early diagnosis and proper management by the doctors of both the specialties. These dermatological conditions may or may not be related to respiratory illness or may hence be part of total disease process or may be completely separate entity. The aim of this study was to find out skin manifestations of various respiratory diseases and analyse dermatological disorders in children referred from Paediatric Department having respiratory symptoms.
\end{abstract}

Methods: An observational cross sectional hospital based study involving inpatients and outpatients referred from Paediatrics to Dermatology Department having respiratory illness and skin lesions was undertaken between January 2019 to December 2020. Details of skin disease were recorded. The descriptive statistical analysis was expressed in frequency and percentage and Chi square test was applied to determine significance among variables.

Results: Total 437 patients were included in the study. The most common diagnosis made by Paediatric $\{160(36.6 \%)\}$ and Dermatology Departments $\{246(56.2 \%)$ was viral exanthema followed by atopic dermatitis $\{77(17.6 \%)\}$. Out of total 65 patients who suffered from bronchial asthma, $59(90.7 \%)$ patients had atopic dermatitis.

Conclusions: Significant paediatric patients with respiratory illnesses have concomitant skin lesions. There is very high percentage of patients having atopic dermatitis among those who had asthma and hence clearly depicts relation between the two diseases.

Keywords: Asthma; Atopic Dermatitis; Respiratory Disorders; Skin Lesions

This work is licensed under creative common attribution 3.0 license

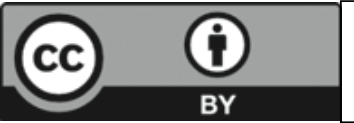

. 


\section{INTRODUCTION}

Paediatric patients with respiratory symptoms having skin lesions are often referred from Paediatric Department to Skin Department for consultations and management. Children may suffer from a primary skin disease or a coexisting respiratory disorder or may have a primary systemic disorder with cutaneous manifestations. ${ }^{1}$ These patients suffer from various conditions which include bronchial asthma, atopic dermatitis (AD), viral infections involving upper respiratory tract infections like measles, rubella, varicella and other conditions all of which may also have skin lesions. A recent study of 9417 children using the National Health Interview Survey found that AD was also linked to increased risk of a variety of extracutaneous infections including streptococcal pharyngitis, viral upper respiratory infection, influenza, pneumonia, sinus infections and varicella. $^{2}$

It has been noted in various studies that there is a relative inability of the doctors of other specialties to diagnose skin conditions accurately and hence patients are referred. This generally leads to marked changes in diagnoses and treatment after dermatology consultation. ${ }^{3}$ Knowledge about skin and respiratory manifestations will lead to early diagnosis and proper management by the doctors of both the specialities. ${ }^{4}$

This study was conducted to find out the types of diseases referred from Paediatric Department and their correlation with dermatological disorders. It was intended to find whether these dermatological conditions were related to respiratory illness or not and hence were a part of total disease process or whether these skin conditions had no relation with respiratory symptoms. This is a novel study done in Nepal. Even though studies have been done with a particular disease but study on children having respiratory symptoms with skin lesions has not been done in Nepal. Hence this study will give new dimensions in early detection of skin disease with respiratory illness. The aim of this study was to find out skin manifestations of various respiratory diseases and analyse dermatological disorders in children referred from Paediatric Department having respiratory symptoms.

\section{METHODS}

This was an observational cross sectional hospital based study. All the referred inpatients and outpatients from Paediatric Department to Department of Dermatology, Shree Birendra Hospital, Chhauni suffering from respiratory illness and having skin lesions between January 2019 to December 2020 were included in the study. Details of skin disease with associated respiratory symptoms were recorded. Patients with positive findings were treated in the department after examination and needful investigations. Those patients who attended Dermatology OPD without referral from Paediatric Department or who didn't have respiratory symptoms were excluded from the study. Definite pattern of types of skin lesions, distribution of lesions and their evolution in the disease process was observed. Informed consent and ethical clearance was taken from Institution Review Board (Ref no.245 reg.366). The statistical analysis was done using SPSS (Statistical Package of Social Sciences) Version 20.0 Statistical Analysis Software. The descriptive statistical analysis of the study was done after the collection of data and results were expressed in frequency and percentage and Chi square test was applied to determine significance among variables.

\section{RESULTS}

A total of 437 patients participated in the study, out of which 206 (47.1\%) were males and $231(52.9 \%)$ were females. There were $46(10.5 \%)$ infants, 83 (19\%) toddlers, 105 (24\%) school children, 144 (33\%) preadolescents and 59 (13.5\%) adolescents. Total $315(72.0 \%)$ patients had lesions on the skin which were associated to their respiratory disorders and $120(28.0 \%)$ patients had skin lesions which were not related to respiratory disease. Patients with most common diagnosis referred by Paediatric Department was viral exanthema 160 (36.6\%), followed by upper respiratory tract infection (URTI) 102 (23.3\%), chest infection 91 (20.8\%), asthma $65(14.9 \%)$, and pulmonary tuberculosis (PTB) 19 (4.3\%). Distribution of the patients according to age and diagnosis is depicted in the table below (Table 1).

A total number of 98 patients were diagnosed as varicella in the Paediatric Department out of which 
Table 1. Distribution of the patients according to age and diagnosis in the Paediatric Department

\begin{tabular}{|c|c|c|c|c|c|c|}
\hline Age Group & $\begin{array}{l}\text { Asthma } \\
(n=65)\end{array}$ & $\begin{array}{l}\text { Chest Infection } \\
\qquad(\mathrm{n}=91)\end{array}$ & $\begin{array}{c}\text { URTI } \\
(n=102)\end{array}$ & $\begin{array}{c}\text { PTB } \\
(n=19)\end{array}$ & $\begin{array}{l}\text { Viral Exanthema } \\
\qquad(\mathrm{n}=160)\end{array}$ & $\begin{array}{c}\text { Total } \\
\mathbf{N}=437\end{array}$ \\
\hline Infant & $15(23 \%)$ & $5(5.4 \%)$ & $18(17.6 \%)$ & $0(0 \%)$ & $8(5 \%)$ & 46 \\
\hline Toddler & $17(26.1 \%)$ & $22(24.1 \%)$ & $18(17.6 \%)$ & $0(0 \%)$ & $26(16.2 \%)$ & 83 \\
\hline School Going & $11(16.9 \%)$ & $25(27.4 \%)$ & $22(21.5 \%)$ & $2(10.5 \%)$ & $45(28.1 \%)$ & 105 \\
\hline Preadolescent & $17(26.1 \%)$ & $27(29.6 \%)$ & $33(32.3 \%)$ & $10(52.6 \%)$ & $57(35.6 \%)$ & 144 \\
\hline Adolescent & $5(7.6 \%)$ & $12(13.1 \%)$ & $11(10.7 \%)$ & $7(36.8 \%)$ & $24(15 \%)$ & 59 \\
\hline
\end{tabular}

maximum were in the preadolescent group 35 $(35.7 \%)$. Similarly most common diagnosis made by Dermatology Department which was associated with respiratory symptoms was viral exanthema $246(56.2 \%)$ followed by AD 77 (17.6\%). Other diagnosis not related to respiratory symptoms were scabies $36(8.2 \%)$, acne vulgaris (AV) 23 (5.3\%), diaper dermatitis $15(3.4 \%)$, acute urticaria 13 $(3 \%)$, drug rash $10(2.3 \%)$, portwine stain $9(2.1 \%)$, hand, foot and mouth disease (HFMD) 8 (1.8\%) and cutaneous candidiasis $8(1.8 \%)$. Distribution of the patients according to age and diagnosis in Dermatology Department is depicted below (Table 2).

Out of 98 patients who were diagnosed as varicella in the Paediatric Department, 95 (96.9\%) patients were diagnosed varicella in Dermatology Department. Comparison of the diagnosis made at
Department of Paediatrics with that made at Department of Dermatology has been depicted as follows (Table 3).

Out of 437 patients, 160 (36.6\%) were diagnosed as viral exanthema in Paediatric Department and 246 $(56.2 \%)$ were diagnosed as viral exanthema in Dermatology Department and there was significant difference in the diagnosis made in Paediatric Department as compared to Dermatology Department. Chi square test was applied and $\mathrm{p}$ value was $<0.001$. And of those 160 patients who were diagnosed as viral exanthema in Paediatric Department 62 (38.5\%) patients had maculopapular rash with fever and cough. A total of 95 (21.7\%) patients of total 437 patients were diagnosed varicella in both the Departments and these patients had erythematous papules, vesicles and pustules on the skin with erosions on oral mucosa. Out of 102

Table 2. Distribution of the patients according to age and diagnosis done in Dermatology Department

\begin{tabular}{|c|c|c|c|c|c|}
\hline Disease & Infant & Toddler & School Going & Preadolescent & Adolescent \\
\hline $\operatorname{AD}(n=77)$ & $15(19.4 \%)$ & $23(29.8 \%)$ & $18(23.3 \%)$ & $20(25.9 \%)$ & $1(1.32 \%)$ \\
\hline Scabies $(n=36)$ & $2(5.5 \%)$ & $3(8.3 \%)$ & $7(19.4 \%)$ & $18(50 \%)$ & $6(16.6 \%)$ \\
\hline $\mathrm{AV}(\mathrm{n}=23)$ & $0(0 \%)$ & $0(0 \%)$ & $0(0 \%)$ & $7(30.4 \%)$ & $6(16.6 \%)$ \\
\hline Cutaneous candidiasis $(n=8)$ & $2(25 \%)$ & $5(62.5 \%)$ & $1(12.5 \%)$ & $0(0 \%)$ & $0(0 \%)$ \\
\hline Viral Exanthema $(\mathrm{n}=246)$ & $17(6.9 \%)$ & $42(17 \%)$ & $75(30.5 \%)$ & $85(34.5 \%)$ & $27(10.9 \%)$ \\
\hline Diaper dermatitis $(n=15)$ & $8(53.4 \%)$ & $7(46.6 \%)$ & $0(0 \%)$ & $0(0 \%)$ & $0(0 \%)$ \\
\hline Portwine Stain $(\mathrm{n}=9)$ & $2(22.2 \%)$ & $3(33.3 \%)$ & $0(0 \%)$ & $2(22.2 \%)$ & $2(22.2 \%)$ \\
\hline Drug rash $(\mathrm{n}=10)$ & $0(0 \%)$ & $0(0 \%)$ & $2(20 \%)$ & $5(50 \%)$ & $3(30 \%)$ \\
\hline Urticaria $(\mathrm{n}=13)$ & $0(0 \%)$ & $0(0 \%)$ & $2(15.4 \%)$ & $7(53.8 \%)$ & $4(30.8 \%)$ \\
\hline Total $(\mathrm{N}=437)$ & $46(10.5 \%)$ & $83(18.9 \%)$ & $105(24 \%)$ & $144(32.9 \%)$ & $59(13.5 \%)$ \\
\hline
\end{tabular}


Table 3. Comparison of the diagnosis made at Department of Paediatrics with that made at Department of Dermatology

\begin{tabular}{|c|c|c|c|c|c|c|}
\hline \multirow{2}{*}{$\begin{array}{l}\text { Diagnosis by } \\
\text { Department of } \\
\text { Dermatology }\end{array}$} & \multicolumn{6}{|c|}{ Diagnosis by Department of Paediatrics } \\
\hline & Asthma & Chest infection & Viral exanthema & URTI & PTB & Total \\
\hline $\mathrm{AD}$ & $59(90.7 \%)$ & $13(14.2 \%)$ & $0(0 \%)$ & $5(4.9 \%)$ & $0(0 \%)$ & 77 \\
\hline Scabies & $2(3 \%)$ & $21(23 \%)$ & $1(0.62 \%)$ & $11(10.7 \%)$ & $1(5.2 \%)$ & 36 \\
\hline AV & $3(4.6 \%)$ & $8(8.7 \%)$ & $2(1.25 \%)$ & $5(4.9 \%)$ & $5(26.3 \%)$ & 23 \\
\hline Cutaneous candidiasis & $0(0 \%)$ & $5(5.4 \%)$ & $0(0 \%)$ & $3(2.9 \%)$ & $0(0 \%)$ & 8 \\
\hline Viral exanthem & $0(0 \%)$ & $31(34.0 \% \%)$ & $155(96.8 \%)$ & $60(58.8 \%)$ & $0(0 \%)$ & 246 \\
\hline Diaper dermatitis & $0(0 \%)$ & $7(7.6 \%)$ & $0(0 \%)$ & $8(7.8 \%)$ & $0(0 \%)$ & 15 \\
\hline Portwine stain & $0(0 \%)$ & $4(4.3 \%)$ & $0(0 \%)$ & $5(4.9 \%)$ & $0(0 \%)$ & 9 \\
\hline Drug rash & $1(1.5 \%)$ & $0(0 \%)$ & $2(1.25 \%)$ & $0(0 \%)$ & $7(36.8 \%)$ & 10 \\
\hline Urticaria & $0(0 \%)$ & $2(2.1 \%)$ & $0(0 \%)$ & $5(4.9 \%)$ & $6(31.5 \%)$ & 13 \\
\hline Total & 65 & 91 & 160 & 102 & 19 & 437 \\
\hline
\end{tabular}

patients who were diagnosed URTI in Paediatric Department $60(58.8 \%)$ were diagnosed as viral exanthema in Dermatology Department.

\section{DISCUSSION}

This study was conducted to find out the skin manifestations of various respiratory diseases and to analyse the dermatological disorders in children referred from Paediatric Department having respiratory symptoms. Skin manifestations among respiratory illness in children are common. Moleyar VS and Noojibail A classified skin disorders with lung involvement into the following categories ${ }^{4}$ :

1. Congenital / developmental disorders with cutaneous and pulmonary manifestations

2. Primary dermatological diseases with pulmonary manifestations

3. Primary pulmonary diseases with cutaneous manifestations

4. Miscellaneous conditions involving skin and lungs

5. Skin changes due to drugs used to treat respiratory diseases

A total of 437 participants who were referred from Paediatric Department having respiratory symptoms and skin lesions were involved in this study and we tried to find out about miscellaneous conditions involving these two systems. It was also noted that out of all the 437 patients who were referred to our department, $315(72.0 \%)$ had various skin conditions which were related to respiratory disorders. The main conditions which were related were bronchial asthma and atopic dermatitis, chest infection and upper respiratory tract infections with viral exanthema.

It has been shown in various studies that asthma and $\mathrm{AD}$ are closely related. It is also noted that patients with $\mathrm{AD}$ have an increased risk of asthma. ${ }^{5}$ It is mainly attributed to genetic risk variants and environmental factors. ${ }^{6,7}$ There is a shared immune response in asthmatic and AD patients with type 2 immunity and raised IgE levels and this may to some extent explain their coexistence. ${ }^{8,9}$ We found that out of 65 patients who suffered from asthma 59 (90.7\%) had $\mathrm{AD}$ and $13(14.2 \%)$ patients who suffered from AD also had chest infections. Even though chest infection alone may not be responsible for triggering or causing $\mathrm{AD}$ but it has been shown in various studies that patients having asthma and $\mathrm{AD}$ are more prone to infections. The main features of skin manifestations in $\mathrm{AD}$ patients were erythematous papules with excoriations which involved mainly flexural areas. Involvement of face was mainly noted in toddlers. Generalised dryness of skin was seen in these patients. 
The most common condition after viral exanthema referred from the Paediatric Department was URTI $\{102(23.3 \%)\}$ and out of these, $60(58.8 \%)$ suffered from viral exanthema. A total of 246 (56.3\%) patients were diagnosed as viral exanthema in our department, whereas a total of $160(36.7 \%)$ patients were diagnosed as viral exanthema in the Paediatric Department ( $\mathrm{p}$ value $<$ $0.001)$. The patients usually first present in the Paediatric Department with sore throat and fever which is followed by skin rash and out of 102 patients who were diagnosed URTI in Paediatric Department, $60(58.8 \%)$ were diagnosed as viral exanthema in our department. Discrepancy in the diagnosis of between Paediatric Department and Dermatology Department could be either because the patients come to Dermatology Department one to three days after referral from Paediatric Department which leads change in dermatologic clinical picture or it could be due to a lack of knowledge about correlation between skin rash and respiratory symptoms. These patients had maculopapular lesions, fever and cough.

Skin rash along with fever is a common finding in children. This may be attributed to a large number of infectious and noninfectious diseases. Skin rashes of various types are common finding in many viral infections. ${ }^{10}$ Viral exanthema is a nonspecific rash, commonly characterised by generalised eruption of erythematous papules and / or macules. ${ }^{11}$ Usually these rashes are benign and in most of the cases, they are correlated with selflimited disease. ${ }^{12}$ Morphology of rashes in patients with febrile exanthema is important which includes shape, size, colour, site and distribution of lesions, progression, tenderness, rise in temperature and desquamation, because this is the basis of making a differential diagnosis clinically. Different viral agents can cause similar skin reactions, while one viral agent may lead to different types of rash. ${ }^{10}$

A total of 95 patients were diagnosed with varicella in both the departments. The patients with varicella came with fever and multiple erythematous papules, vesicles and pustules. Erosions were also noted in oral mucosa. Sore throat was one of the prominent features in these patients. The most important characteristics of varicella include central distribution, umbilication and presence of different highly pruritic skin rashes. ${ }^{10}$

Our study does have some limitations. Our study has been done in military hospital which caters to military personnel, their dependents and ex army personnels and their dependents and these people belong to better socio-economic strata in Nepal as compared to general population of our country. Hence, the result which we have got may not be representative of the entire scenario of Nepal. We also have not done the follow up of the skin lesions as well as respiratory symptoms, which may have significance. However, we hope that the future larger, multicentric studies on this subject should shed more light upon the correlation between skin and respiratory symptoms in children.

\section{CONCLUSIONS}

Many children with respiratory illnesses have concomitant skin lesions. In regards to skin lesions seen in children in Paediatric Department, it would be more prudent to get further confirmation from Dermatology Department. Viral exanthema and atopic dermatitis were the commonest skin lesions in children with respiratory symptoms referred from Paediatric Department. There is strong correlation between children with bronchial asthma and atopic dermatitis.

\section{REFERENCES}

1. Garg T, Ahmad R, Basu S, Chander R. Clinical spectrum of dermatological disorders in children referred from pediatrics department. Indian J Paediat Dermatol. 2019;20:212-8. DOI: 10.4103/ijpd.IJPD_11_18 
2. Silverberg JI, Silverberg NB. Childhood atopic dermatitis and warts are associated with increased risk of infection: a U.S. population-based study. J Allergy Clin Immunol. 2014;133:1041-7. DOI: 10.1016/j.jaci.2013.08.012

3. Mathias RC, Jayaseelan E, Augustine M. Spectrum of pediatric dermatological emergencies at a tertiary care hospital in India: A descriptive study. Int J Dermatol. 2013;52:27-31. DOI: 10.1111/j.1365-4632.2011.05247.x

4. Moleyar VS, Noojibail A. Disease with skin and lung involvement: Pulmonologist's perspective. Med J DY Patil Vidyapeeth. 2020;13:106 -12. DOI: 10.4103/mjdrdypu.mjdrdypu_62_19

5. Andersen YMF, Egeberg A, Gislason GH, Skov L, Thyssen JP. Burden of respiratory comorbidities in patients with atopic dermatitis and psoriasis. Br J Dermatol. 2017;177(4):145-6. DOI: 10.1111/bjd.15489

6. Paller AS, Spergel JM, Mina-Osorio P, Irvine AD. The atopic march and atopic multimorbidity: many trajectories, many pathways. J Allergy Clin Immunol. 2019;143(1):46-55. DOI: 10.1016/j.jaci.2018.11.006

7. Ferreira MA, Vonk JM, Baurecht H, Marenholz I, Tian C, Hoffman JD, et al. Shared genetic origin of asthma, hay fever and eczema elucidates allergic diseasebiology. Nat Genet. 2017;49(12):1752-7. DOI: 10.1038/ng.3985

8. Han H, Roan F, Ziegler SF. The atopic march: current insights into skin barrier dysfunction and epithelial cellderived cytokines. Immunol Rev. 2017;278:116-30. DOI: 10.1111/imr.12546

9. Ravnborg N, Ambikaibalan D, Agnihotri G, Price S, Rastogi S, Patel KR, et al. Prevalence of asthma in patients with atopic dermatitis: A systematic review and meta-analysis. J Am Acad Dermatol. 2021 Feb;84(2):471-8. DOI: $10.1016 /$ j.jaad.2020.02.055

10. Saffar JM, Rokni GR, Raeasian M. Paediatric Viral Exanthema: A Review Article. J Pediatr Rev. 2017;5(2):9487. DOI: $10.5812 /$ jpr.9487

11. Sarkar R, Mishra K, Garg VK. Fever with rash in a child in India. Indian J Dermatol Venereol Leprol. 2012;78(3): 251-62. DOI: 10.4103/0378-6323.95439

12. Salavastru CM, Stanciu AM, Fritz K, Tiplica GS. A burst in the incidence of viral exanthems. Indian Dermatol Online J. 2014 Apr;5(2):144-7. DOI: 10.4103/2229-5178.131083. 